\title{
The Cytology of the Gram-positive Cocci
}

\author{
BY K. A. BISSET \\ The Department of Bacteriology, University of Birmingham
}

\begin{abstract}
SUMMARY: The long-chained and short-chained variants of Streptococcus pyogenes, Str. viridans and Str. faecalis possess a structure closely resembling that of rough and smooth bacillary variants. Cocei of the long-chained strains are frequently divided by transverse cell walls into two cells, each containing a single chromatinic body. Short-chained strains fail to form transverse cell walls, the cocci dividing by constriction; they are unicellular and usually contain a pair of chromatinic bodies. Analogous types occur in Staphylococcus aureus and Staph. albus. In one of these types the cells contained a well-defined central granule, dividing with the coccus.
\end{abstract}

It has been pointed out (Bisset, 1938) that there is a close analogy between the smooth and rough morphological types of rod-shaped bacteria on the one hand, and the short-chained and long-chained streptococci and pneumococci on the other. The long-chained streptococci, like the rough bacilli, adhere to one another after cell division and form a 'Medusa-head' colony (Pl. 1, fig. 1) whereas the short-chained cocci, like the smooth bacilli, separate more or less completely, and form relatively structureless colonies (Pl. 1, fig. 2). This variation is entirely independent of those usually described as $\mathbf{S} \rightarrow \mathbf{R}$ in the pneumococcus, or 'matt' $\rightarrow$ 'glossy' in the streptococcus, each of which is concerned only with the capsular material. In a recent paper (Bisset, 1947) the author has shown that rough variants of species both in the Bacteriaceae and the Bacillaceae are often divided by transverse cell walls and septa into several cells, each containing a single chromatinic body. The unicellular smooth variants contain a pair of bodies and do not form transverse cell walls. In the present study the minute structure of the two types of streptococcus, and of certain types of staphylococcus, is compared with that of the bacillary variants.

Nuclear structures have been reported in various Gram-positive cocci (Piekarski, 1938; Robinow, 1942; Knaysi, 1942), and single, double, and multiple nuclei have been described, although not in a streptococcus. Knaysi \& Mudd (1943) failed to demonstrate nuclear structures in a streptococcus with the electron microscope, but claimed to have done so in a staphylococcus.

\section{METHODS}

The osmic-acid, HCl-Giemsa, and tannic-acid-violet techniques of Robinow (1945) were used throughout, and water mounts were always employed. The value of these techniques in the examination of bacterial chromatinic apparatus and cell walls depends upon the removal of the staining capacity of those portions of the cell which it is not intended to demonstrate. By hydrolysis with $\mathrm{HCl}$, the polysaccharide material which probably forms the major portion of the cell wall is rendered unstainable and at least partially destroyed. After this treatment bacteria appear much reduced in size by the loss of this surface 
material. Tannic acid leaves the cell wall unharmed, and destroys or renders unstainable the protein contents of the cell, which appears as if empty. Taken together, these methods probably give a reasonable picture of the structure of bacteria.

The streptococci studied were stock cultures of Streptococcus pyogenes, Str. viridans and Str. faecalis used for the production of Lancefield grouping sera, and strains recently isolated from both the human subject and dogs. They were of various antigenic groups and were either alpha- or beta-haemolytic. Neither of these characters was correlated with the morphological variation under examination; the strains were either long-chained or short-chained upon isolation and some had since produced variants. Colony form and habit of chain length was examined by means of impression preparations (Bisset, 1938).

Strains of Staphylococcus aureus and Staph. albus were examined. Some strains were stock cultures, and others were newly isolated from pathological material or from random, air-borne contaminants. A stock culture of Sarcina lutea was also examined. Cultures were made upon horse-blood agar plates, and were examined when about $24 \mathrm{hr}$. old.

\section{OBSERVATIONS}

When stained by tannic-acid-violet to demonstrate the cell walls, the two types of streptococcus were markedly different in appearance. The long-chained forms, which were mainly Streptococcus pyogenes and Str. viridans, were almost completely spherical, and a large proportion of cocci had obvious transverse septa, continuous with the cell wall. Recently divided cocci were closely applied together, and no great degree of constriction was observed in their division (Pl. 1, fig. 3). The short-chained forms, which were strains of Str. pyogenes and Str. faecalis, were lanceolate in outline and without transverse septa. Marked constrictions appeared between the dividing cocci and separation was complete or almost so (Pl. 1, fig. 4). The newly formed cell walls between recently divided cells of this type were unmistakably different from the septa, which, in the long-chained forms, halved otherwise entire cocci. The occasional long filaments which appeared in both types of coccus, as also in both $\mathbf{S}$ and $\mathbf{R}$ bacilli, occasionally exhibited what appeared to be transverse septa, even in the short-chained types. As the same filament might also show signs of division by constriction, however, it is probable that these apparent septa were indicative of past, rather than future division, and merely marked the failure of the new sub-units to separate after the formation of the new cell wall (Pl. 1, fig. 5).

When stained with Giemsa, after hydrolysis for about $2 \mathrm{hr}$., long-chained cocci showed a varied appearance (Pl. 1, fig. 6). In the majority of cells the protoplasm retained its staining capacity, the most obvious feature being the unstained bar, representing the septum. Where hydrolysis was more complete, the only structures retaining the stain were relatively long, narrow chromatinic bodies, arranged in pairs. These pairs were sometimes so close together as to be almost touching, and sometimes more widely separated. 
By superimposing tracings of photographs, taken at the same magnification, it was possible to establish that the former pairs were capable of being contained within a single coccus, presumably on the point of division, whereas the latter were so spaced as to lie in each half of a divided or septate organism (Fig. 1). In the short-chained form stained by acid-Giemsa, the majority of cocci contained two bodies, which, though apparently spherical, were probably merely unresolved. A minority contained only one (Pl. 2, fig. 7; Fig. 2).

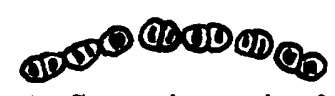

Fig. 1. Composite tracing from Pl. 1, figs. 3 and 6.

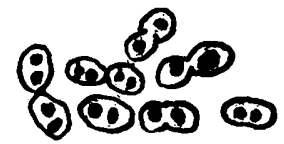

Fig. 2. Composite tracing from Pl. 1, fig. 4 and Pl. 2, fig. 7 .

The majority of strains of both Staph. aureus and Staph. albus examined bore a close resemblance, in their minute structure, to long-chained streptococci. Well-marked transverse septa were observed (Pl. 2, fig. 8) their position being indicated in the Giemsa preparations by an unstained bar across the middle of the coccus (Pl. 2, fig. 9). Unlike the streptococci, however, the succeeding division was often at right angles to the preceding one, and it was common to find a recently divided coccus in which one of the daughter cells had subdivided in this manner, before complete separation had occurred (Pl. 2, $a$ in figs. 8 and 9). Cells of abnormal length were not found, but occasional cocci, greatly swollen. in all dimensions, were to be seen. In the ordinary processes of growth the increase in size was three-dimensional, and not by elongation as in the streptococci. In staphylococci with this morphology a unicellular coccus was the exception rather than the rule. Chromatinic bodies were even less clearly defined than in the long-chained streptococci, appearing merely as comparatively heavily stained central areas in the cytoplasm. The cytoplasm strongly resisted hydrolysis with $\mathrm{HCl}$ and retained its staining capacity after many hours. The second morphological type of staphylococcus was much less commonly found, although it included saprophytic albus strains and haemolytic aureus strains isolated from pathological material. The cells contained a clearly defined granule, central or slightly eccentric in position (Pl. 2, fig. 10). Division of the granule preceded that of the coccus, and growth was mainly, although not exclusively, by elongation. This type of coccus did not form transverse septa, and was apparently unicellular (Pl. 2, fig. 11). Morphologically this type of staphylococcus was similar to the strain of Sarcina lutea examined, although only the Sarcina was arranged in the typical packet-of-eight. The existence of discrete, central chromatinic bodies in this genus is already fully recorded (Piekarski, 1938; Robinow, 1942).

\section{DISCUSSION}

The demonstration of chromatinic bodies in Streptococcus and Staphylococcus by means of Robinow's modification of Feulgen's reaction, serves merely to bring these genera into line with the other bacterial groups which have been 
studied in this way. A separate discussion of the significance of the finding is not appropriate to this paper. The present observations are of assistance, however, in the interpretation of some of the previously recorded observations upon the nuclear apparatus of staphylococci. Knaysi (1942) appears, from his photographs, to have been observing a septate staphylococcus, although the septa are not described. The multiple granules demonstrated in a staphylococcus by Knaysi \& Mudd (1943), by means of the electron microscope, may possibly be interpreted as the effect of desiccation upon the same type of coccus in a multicellular condition, as in Fig. 5, no. 2.
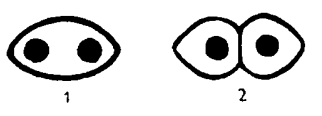

Fig. 3
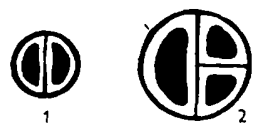

Fig. 5

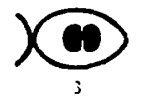

i

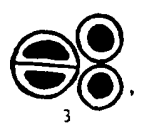

3$$
\text { . }
$$

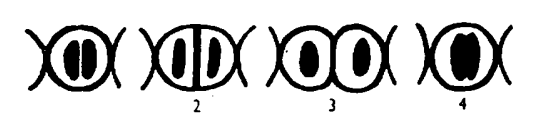

Fig. 4
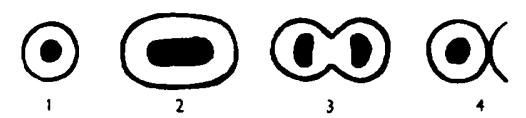

Fig. 6

Fig. 3. Short-chained streptococcus in process of division. Suggested interpretation.

Fig. 4. Long-chained streptococcus in process of division. Suggested interpretation.

Fig. 5. Septate staphylococcus in process of division. Suggested interpretation.

Fig. 6. Non-septate staphylococcus in process of division. Suggested interpretation.

It is of interest to observe that the parallel between smooth and rough variants in the bacillary genera, and short- and long-chained streptococci, appears to extend to their minute structure. In both groups, the variant which adheres in chains after division, and consequently forms 'Medusa-head' colonies, also produces multicellular bacilli or cocci, possessing transverse cell walls, and with each cell containing a single chromatinic body, except, probably, immediately before division (Fig. 4). Similarly, in both groups, the variant which separates completely after division fails to form transverse cell. walls, and divides by constriction, producing unicellular bacteria, each of which contains a pair of chromatinic bodies (Fig. 3). This resemblance between the streptococci and the bacillary genera is enhanced by the observation that both types of streptococcus grow by elongation, and when normal cell division fails to take place produce long, filamentous elements of normal breadth, analogous to those occurring in cultures of bacilli. In fact, the only basic difference between a streptococcus and a bacillus is average cell length.

Although the staphylococci also produced septate and non-septate forms, the analogy cannot at present be carried any further. The septate form does indeed resemble closely the long-chained streptococcus, but differs in that it is a true, radially symmetrical coccus, increasing in size in all dimensions, and capable of dividing in any plane (Fig. 5). The non-septate form is quite unlike either of the streptococcal forms in its possession of a single chromatinic granule, which, from its resemblance to the acknowledged nuclear apparatus of Sarcina, can fairly be regarded as a discrete nucleus (Fig. 6). 


\section{REFERENCES}

Bisset, K. A. (1938). The structure of 'rough' and 'smooth' colonies. J. Path. Bact. 47, 223.

Bisset, K. A. (1947). The cytology of smooth and rough variation in bacteria. J. gen. Microbiol. 2, 83.

KNAYSI, G. (1942). The demonstration of a nucleus in the cell of a staphylococcus. J. Bact. 43, 365.

KNAYSI, G. \& MuDD, S. (1943). Internal structure of certain bacteria as revealed by the electron microscope-a contribution to the study of the bacterial nucleus. J. Bact. 45, 349.

Piekarski, G. (1938). Zytologische Untersuchungen an Bakterien im ultravioletten Licht. Zbl. Bakt. (1. Abt. Orig.), 142, 69.

Robinow, C. F. (1942). A study of the nuclear apparatus of bacteria. Proc. Roy. Soc. B, 130, 299.

Robinow, C. F. (1945). Addendum to: The Bacterial Cell, Dubos, R. J. Harvard University Press.

\section{EXPLANATION OF PLATES}

\section{Plate 1}

Fig. 1. Long-chained streptococcus colony, impression preparation. $\times 500$.

Fig. 2. Short-chained streptococcus colony, impression preparation. $\times 500$.

Fig. 3. Long-chained streptococcus showing transverse septa. Tannic-acid-violet. $\times 3000$.

Fig. 4. Short-chained streptococcus dividing by constriction. Tannic-acid-violet. $\times 3000$.

Fig. 5. Short-chained streptococcus. The long filament shows a point of constriction near one end, and an apparent septum, probably representing an uncompleted division. Tannic-acid-violet. $\times 3000$.

Fig. 6. Long-chained streptococcus. The central group is fully hydrolysed and only the pairs of chromatinic bodies are stained. In the rest of the field the entire cytoplasm of the cell is stained in most cases, and the unstained gap, representing the septum, is clearly shown. Acid-Giemsa. $\times 3000$.

\section{Plate 2}

Fig. 7. Short-chained streptococcus showing double chromatinic bodies in most of the cells. Acid-Giemsa. $\times \mathbf{3 0 0 0}$.

Fig. 8. Septate staphylococcus. $a$ is a coccus dividing at right angles to the previous division. Tannic-acid-violet. $\times 3000$.

Fig. 9. Septate staphylococcus. $a$ is a coccus producing a secondary septum at right angles to the primary one. Acid-Giemsa. $\times 3000$.

Fig. 10. Non-septate staphylocóccus. Acid-Giemsa. $\times 3000$.

Fig. 11. Non-septate staphylococcus. Tannic-acid-violet. $\times 3000$. 
Journal of General Microbiology, Vol. 2, No. 2
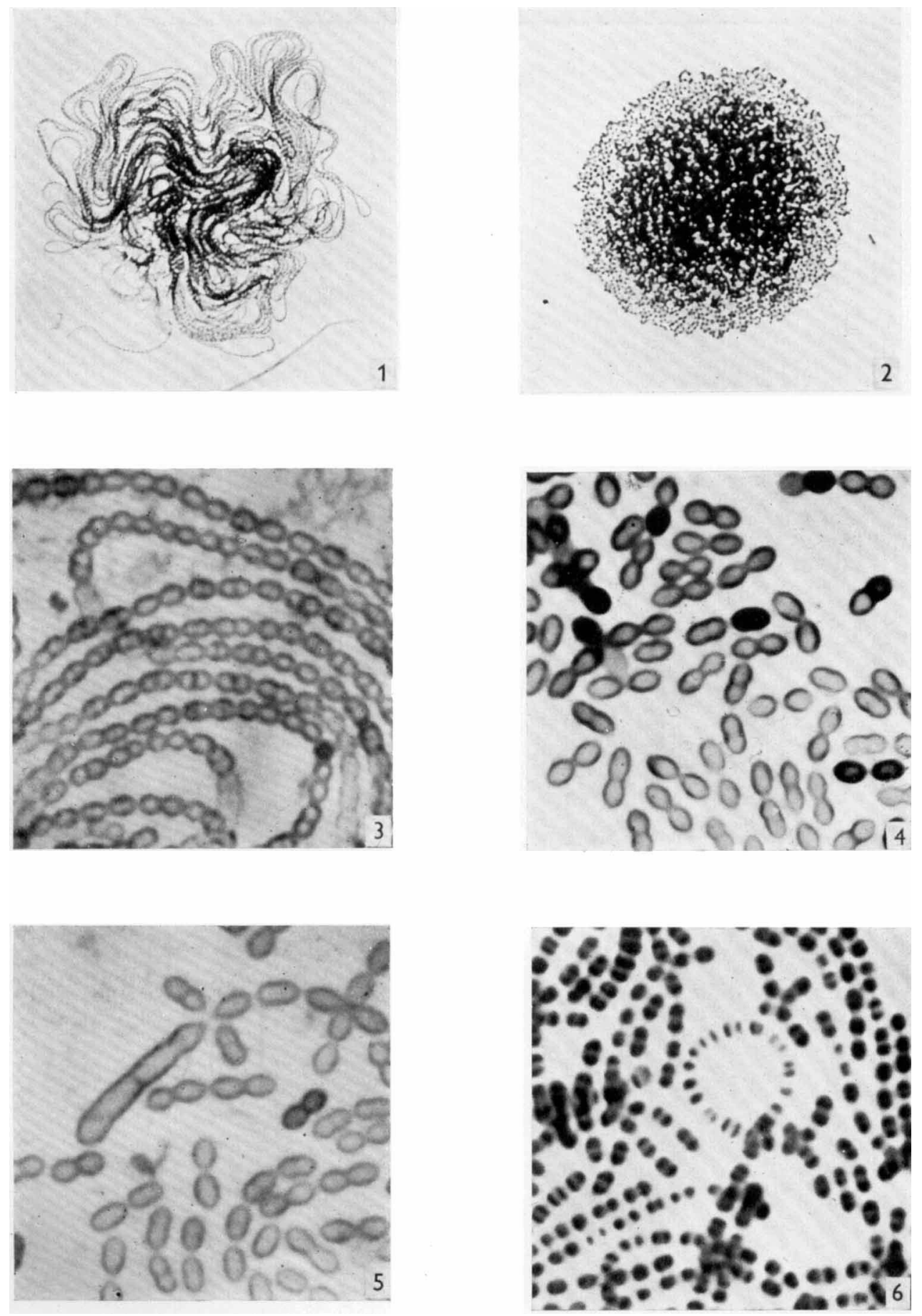

Figs. 1-6

K. A. Bisset-The cytology of the gram-positive cocci. Plate 1 
Journal of General Microbiology, Vol. 2, No. 2
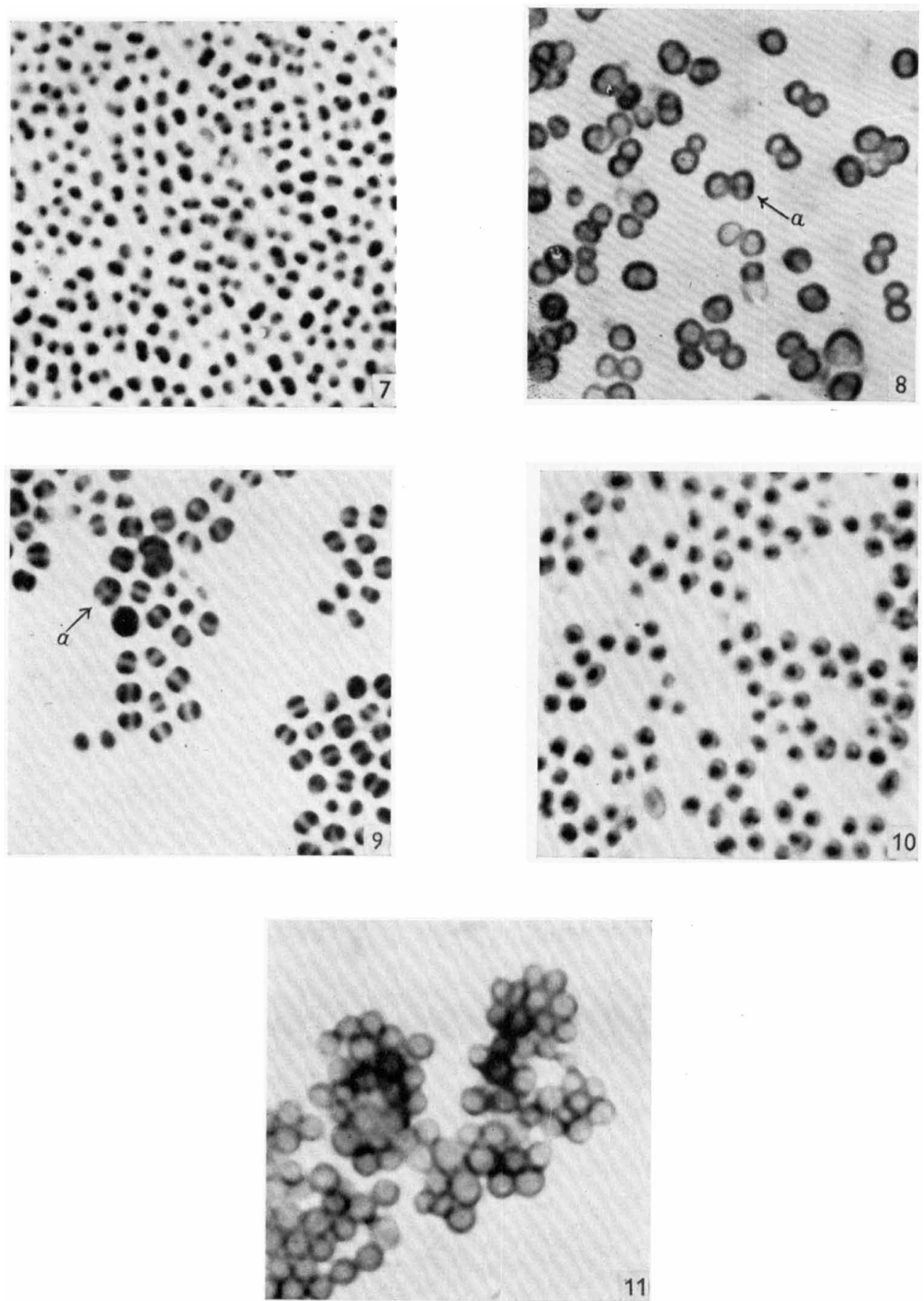

Fig. 7-11

K. A. Bisset-The cytology of tire gram-positive cocci. Plate 2 